\title{
The effect of sulphur dioxide exposure on indices of heart rate variability in normal and asthmatic adults
}

\author{
W.S. Tunnicliffe*, M.F. Hilton*, R.M. Harrison", J.G. Ayres*
}

\begin{abstract}
The effect of sulphur dioxide exposure on indices of heart rate variability in normal and asthmatic adults. W.S. Tunnicliffe, M.F. Hilton, R.M. Harrison, J.G. Ayres. (C)ERS Journals Ltd 2001.

ABSTRACT: Sulphur dioxide $\left(\mathrm{SO}_{2}\right)$ is an important air pollutant and causes bronchoconstriction in normal and asthmatic adults. This paper has explored the autonomic consequences of $\mathrm{SO}_{2}$ exposure using the spectral analysis of heart rate variability.

Electrocardiogram recordings were made in 12 normal and 12 asthmatic adults undergoing pollutant exposures. Exposures were of a $1 \mathrm{~h}$ duration, double blind, in random order, $\geqslant 2$ weeks apart and included air and 200 parts per billion $\mathrm{SO}_{2}$. Spectral analysis of $\mathbf{R}-\mathbf{R}$ intervals was performed.

$\mathrm{SO}_{2}$ exposure was associated with an increase in total power (TP) and high (HF) and low frequency $(\mathrm{LF})$ power in the normal subjects, and a reduction in these indices in the subjects with asthma. The difference in $\mathrm{TP}$ with $\mathrm{SO}_{2}$ exposure compared to air was $+1730 \mathrm{~ms}^{2}$ in the normal group and $-1021 \mathrm{~ms}^{2}$ asthmatic group $(\mathbf{p}<0.003)$. For HF the respective values were $+964 \mathrm{~ms}^{2}$ and $-539 \mathrm{~ms}^{2}(p=0.02)$ and for $L F,+437 \mathrm{~ms}^{2}$ and -57 $2 \mathrm{~ms}^{2}(p=0.01)$. No change in lung function or symptoms was observed in either group.

This suggests that $\mathrm{SO}_{2}$ exposure at concentrations which are frequently encountered during air pollution episodes can influence the autonomic nervous system. This may be important in understanding the mechanisms involved in $\mathrm{SO}_{2}$ induced bronchoconstriction, and of the cardiovascular effects of air pollution.

Eur Respir J 2001; 17: 604-608.
\end{abstract}

*Heartlands Research Institute, Heartlands Hospital, Bordesley Green East, Birmingham, UK. " Division of Environmental Health \& Risk Management, University of Birmingham, Edgbaston, Birmingham, UK.

Correspondence: J.G. Ayres, Heartlands Research Institute, Heartlands Hospital, Bordesley Green East, B9 5SS, Birmingham, UK. Fax: 441217724259

Keywords: Air pollution health effects

heart rate variability

mechanisms

sulphur dioxide

\section{Received: March 102000}

Accepted after revision December 18 2000
Sulphur dioxide $\left(\mathrm{SO}_{2}\right)$ is a common outdoor air pollutant and is associated with day to day changes in hospitalization rates for lung disease in Europe [1]. While annual mean concentrations in urban areas of the UK are generally in the range of $10-20$ parts per billion (ppb), maximum 1-h means of 200-300 ppb are commonly recorded. Recently, maximum 1-h means $>500 \mathrm{ppb}$ were recorded in Belfast. These concentrations are commonly exceeded in Eastern Europe [2].

In challenge studies, $\mathrm{SO}_{2}$ is capable of producing bronchoconstriction in both normal and asthmatic subjects [3]. Normal subjects vary considerably in their response to this gas, most responding to concentrations of 4,000-5,000 ppb [4], but no effects have been recorded in normal individuals exposed to concentrations $<1,000 \mathrm{ppb}$ [5]. Bronchoconstriction in asthmatic subjects occurs at lower concentrations, changes in lung function being detectable at concentrations of $400 \mathrm{ppb}$ when exposures are combined with exercise [5]. The mechanisms producing bronchoconstriction in humans are relatively poorly understood, but are thought to involve stimulation of irritant receptors in the upper airway [6]. Atropine has been shown to block $\mathrm{SO}_{2}$ induced bronchoconstriction in normal adults [7], suggesting a cholinergic reflex, but this agent is only partially effective in subjects with asthma [8]. Neither the difference in the sensitivity between asthmatics and normals to $\mathrm{SO}_{2}$, nor the differing effects of atropine blockade in these groups have been adequately explained. This questioned whether these observed differences might be explained by differing autonomic responses of these groups to $\mathrm{SO}_{2}$ exposure.

Spectral analysis of heart rate variability (HRV) is now an established clinical and research tool for the noninvasive assessment of autonomic nervous system function in humans [9]. In brief, a continuous electrocardiogram (ECG) is recorded for off-line computer analysis. The recording is edited to remove nonsinus ectopic beats, pauses, artefacts and nonperiodic R-R interval (the time between successive ventricular depolarizations) changes. The R-R intervals are then measured and power spectral density analysis is performed to give information about how power (variance) distributes as a function of frequency. In short-term recordings, three main spectral components are distinguishable; very low frequency (VLF) $(\leqslant 0.04 \mathrm{~Hz})$, low frequency (LF) $(0.04-0.15 \mathrm{~Hz})$ and high frequency (HF) $(0.15-0.4 \mathrm{~Hz})$. In addition, total power (TP) is measured as a sum of these components. The physiological explanation of the VLF component is poorly defined; in contrast, the LF component is recognized as chiefly reflecting sympathetic modulation while the HF component reflects almost exclusively parasympathetic (vagal) modulation. Relative sympathetic and 
parasympathetic balance is reflected in the LF:HF ratio [9].

As part of a series of studies of the effects of pollutant exposures in males, the autonomic consequences of exposure to $200 \mathrm{ppb} \mathrm{SO}_{2}$ in normal and asthmatic adult volunteers was explored. The intention was to determine whether an air pollutant exposure at a relevant concentration might be associated with a detectable change in autonomic nervous system modulation and if so, to characterize the nature of the response in normal and asthmatic subjects.

\section{Subjects and methods}

\section{Subjects}

Twenty-four adult volunteers participating in a study of the respiratory effects of exposure to fine particulate sulphuric acid and ammonium bisulphate, and to $\mathrm{SO}_{2}$ were studied. Half of the subjects had physician diagnosed mild asthma, the others were normal, healthy adults (table 1). None of the volunteers were current smokers and subjects with coexisting cardiovascular disease or who were using cardiovascular medication were excluded. The asthmatic subjects were using only short acting $\beta$-agonists with or without inhaled corticosteroids at a dose not exceeding 400 $\mu \mathrm{g}$ of beclomethasone or equivalent, per day. All users of $\beta$-agonists were required to refrain from their use for a minimum of $4 \mathrm{~h}$ before undergoing each pollutant exposure. The project was approved by the East Birmingham Health Authority research and ethics committee.

\section{Exposures}

Exposures were $\geqslant 2$ weeks apart, of 1-h duration at rest and were conducted at the same time of the day for each individual. The pollutants used were $200 \mathrm{ppb} \mathrm{SO}$, and two doses each of particulate ammonium bisulphate and sulphuric acid; only the results following $\mathrm{SO}_{2}$ are presented here. Bottled medical air (BOC, Manchester, UK) was used for the placebo exposure. All exposures were conducted double blind, in random order via a purpose built, closed circuit head only exposure system [10]. Flow through the system for each exposure was maintained at $120 \mathrm{~L} \cdot \mathrm{min}^{-1}$ to prevent any significant rebreathing within the exposure circuit. The required concentration of $\mathrm{SO}_{2}$ was achieved by blending bottled medical air with bottled 60 ppm $\mathrm{SO}_{2}$ using mass flow controllers (Flow Tech Solutions, Stockport, UK). Verification of the delivered exposure gas concentration was made using an ultraviolet fluorescence gas analyser (API Corp, San Diego, CA, USA). For each exposure, the subject sat in a comfortable chair, with their head contained within the dome of the exposure system. The entry port in the wall of the dome was positioned within the breathing zone and the exit port was in the roof of the dome. A neck seal was achieved with a modified diving suit neck piece.

\section{Measurements}

Symptoms. Subjects were asked to record the degree of eye and throat irritation, cough, wheeze, sputum production and breathlessness before and at the end of each exposure, using a visual analogue scale (VAS) score.

Ventilation. A pneumotachograph (Vitalograph, Buckingham, UK) was incorporated in the exit limb of the exposure circuit, allowing the volume, duration and start time of each breath to be recorded. An oral thermocouple flow sensor (CASE, Biggin Hill, Kent, UK) was worn by the subjects which enabled us to determine the proportional partitioning of oral and nasal ventilation.

Lung function. Subjects performed spirometry before and immediately after their exposures, and at intervals for a further $4 \mathrm{~h}$. Recorded parameters included forced expiratory volume in one second (FEV1), and forced vital capacity (FVC). Lung function measurements were made with a pneumotachograph (Fleisch) and the Vitalograph Spirotrac III system (Buckingham, UK), calibrated at the start of each study day. The best of $\geqslant 3$ technically acceptable blows was taken as the measured value at each time point. European Community Coal and Steel (ECCS) predicted values were used.

Heart rate variability. Subjects wore a Holter recorder (Oxford Medilog 4500, Oxford Instruments, Abingdon, UK) for $30 \mathrm{~min}$ before, and for the duration of each exposure. The ECG data from the continuous Holter recordings were templated.

Outlyers and ectopics were identified and appropriately censored. R-R interval data were resampled at $3.41 \mathrm{~Hz}$ by applying a cubic polynomial and stationarity was approximated by least squares linear regression. Spectral analysis was performed using the fast Fourier transform and the application of a Hanning window of 512 points length. Powers were reported for each 5-min epoch of each exposure for each subject.

Table 1. - Characteristics of study groups

\begin{tabular}{lcccr}
\hline & Age yrs & Sex (M:F) & FEV1 \% pred & FVC \% pred \\
\hline Normals & $34.5(22-49)$ & $5: 7$ & $98.9 \%(78-111 \%)$ & $101.2 \%(80-116 \%)$ \\
Asthmatic & $35.7(20-54)$ & $7: 5$ & $88.5 \%(74-113 \%)$ & $97.2 \%(88-117 \%)$ \\
\hline
\end{tabular}

Data are presented as mean (range) or ratio. M: male; F: female; FEV1: forced expiratory volume in one second; FVC: forced vital capacity; \% pred: percentage of predicted value. 


\section{Data analysis}

The HRV data were examined for stationarity. There was found to be considerable variability over the first four epochs and consequently comparisons have been restricted to data from the last seven epochs of each 1-h exposure.

Within group matched-pair analysis was used to compare the mean HRV spectral indices, the lung function parameters, the measures of heart rate and of ventilation between exposures. Paired t-tests were used for significance testing. Significance testing for between group comparisons was also by t-tests.

\section{Results}

\section{Symptoms, ventilation and lung function}

All exposures were well tolerated and were completed by all subjects. There were no differences in symptom scores in either the normal or the asthmatic group between exposures. In the normal group there were no significant differences in the ventilation parameters measured during the air and $\mathrm{SO}_{2}$ exposures. In the asthmatic group, $\mathrm{SO}_{2}$ exposure was associated with a small but significant increase in mean respiratory frequency relative to placebo $\left(\mathrm{SO}_{2} 16.0\right.$ breaths $\cdot \mathrm{min}^{-1}$, air 15.1 breaths $\cdot \min ^{-1}, \mathrm{p}=0.04,95 \%$ confidence interval (CI) of difference $0.16-1.57$ breaths $\cdot \mathrm{min}^{-1}$ ), but the mean volume breathed did not differ significantly $\left(\mathrm{SO}_{2}\right.$ $318.8 \mathrm{~L}$, air: $311.4 \mathrm{~L} ; \mathrm{p}=0.7$ ). At least $95 \%$ of all breaths were nasal and there was no significant association between the frequency of oral breaths and $\mathrm{SO}_{2}$ exposure in either group. There were no significant changes in FEV1 or other lung function parameters with $\mathrm{SO}_{2}$ exposure in either group. Complete lung function data will be reported elsewhere.

\section{Cardiovascular indices}

There were no significant differences in maximum or minimum heart rates with $\mathrm{SO}_{2}$ exposure in either group (table 2). Examination of the spectral components with $\mathrm{SO}_{2}$ exposure showed a distinct pattern In normal subjects TP, HF and LF were all higher with $\mathrm{SO}_{2}$ exposure compared to air (table $2 ; \mathrm{p}<0.05$ for TP) while in the asthmatic group, all three indices were lower with $\mathrm{SO}_{2}$ exposure. LF:HF ratios were unchanged in both groups for each exposure.
The difference in TP with $\mathrm{SO}_{2}$ exposure compared to air was $+1730 \mathrm{~ms}^{2}$ in the normal group and $-1021 \mathrm{~ms}^{2}$ in asthmatic group $(\mathrm{p}<0.003)$. For HF power the respective values were $+964 \mathrm{~ms}^{2}$ and $-539 \mathrm{~ms}^{2}(\mathrm{p}=0.02)$ and for LF power, $+437 \mathrm{~ms}^{2}$ and $-572 \mathrm{~ms}^{2}(\mathrm{p}=0.01)$.

\section{Discussion}

It has been demonstrated that exposure to $200 \mathrm{ppb}$ $\mathrm{SO}_{2}$ is associated with reduced total, high, and low frequency power in asthmatic subjects and increased total, high and low frequency power in normal subjects. These differences in the autonomic responses of asthmatic and normal adult subjects to $\mathrm{SO}_{2}$ exposure occurred in the absence of detectable changes in symptoms or lung function. This implies that $\mathrm{SO}_{2}$ exposure at levels which can be frequently encountered during air pollution episodes in Europe [1], may have sub clinical effects. This indicates a systemic impact of a pollutant gas which may have implications in determining mechanistic pathways for both the respiratory and nonrespiratory effects of air pollutants.

The mechanisms of the health effects of $\mathrm{SO}_{2}$ are not completely understood. At higher concentrations than employed in this study, $\mathrm{SO}_{2}$ is a powerful bronchoconstrictor, i.e. at concentrations of around 400 $\mathrm{ppb}$ in asthmatics [5] and at concentrations $>1,000$ ppb in normal subjects [4]. Such effects in normal subjects can be completely abolished with anticholinergic drugs, but are only partially reversed in subjects with asthma. These differences have been difficult to explain, but suggest that $\mathrm{SO}_{2}$ may produce bronchoconstriction in normal and asthmatic airways by differing pathways. It has been assumed that some of these effects may be mediated in the peripheral airways but this is unlikely to be the case for the present findings as at the concentration of $\mathrm{SO}_{2}$ employed (200 ppb) little if any of this highly soluble pollutant gas would be expected to penetrate beyond the trachea [11]. This would imply that the upper airways, including the nose, pharynx or larynx may be important in determining these effects.

$\mathrm{SO}_{2}$ can activate rapidly adapting receptors (RARs) and C-fibres [12] in the upper airway and trachea, producing a centrally mediated increase in vagal tone resulting in distal bronchoconstriction. There is also some evidence that laryngeal C-fibre stimulation can result in local airway narrowing [6]. Equally, $\mathrm{SO}_{2}$ may be able to induce local airway narrowing by the direct stimulation of sensory mucosal nerve endings through

Table 2. - Heart rate measures and frequency domain measures of heart rate variability by group

\begin{tabular}{|c|c|c|c|c|}
\hline & \multicolumn{2}{|c|}{ Normal } & \multicolumn{2}{|c|}{ Asthma } \\
\hline & Air & $\mathrm{SO}_{2}$ & Air & $\mathrm{SO}_{2}$ \\
\hline Maximum heart rate beats $\cdot \mathrm{min}^{-1}$ & $94.2(89.8-98.6)$ & $96.6(90.3-102.9)$ & $97.8(91.5-104.3)$ & $94.0(87.3-100.7)$ \\
\hline Minimum heart rate beats $\cdot \mathrm{min}^{-1}$ & $55.42(52.1-58.7)$ & $53.3(49.9-56.8)$ & $53.8(50.5-57.2)$ & $54.8(51.6-57.9)$ \\
\hline Total power $\mathrm{ms}^{2}$ & $4825(2461-7189)$ & $6555(3188-9922) *$ & $3825(2593-5057)$ & $2804(2265-3343)$ \\
\hline High frequency power $\mathrm{ms}^{2}$ & $1708(518-2898)$ & $2672(872-4472)$ & $1141(407-1875)$ & $602(333-871)$ \\
\hline Low frequency power $\mathrm{ms}^{2}$ & $1401(657-2145)$ & $1837(806-2868)$ & $1502(903-2101)$ & $930(741-1119)$ \\
\hline
\end{tabular}

Data are presented as mean (95\% confidence interval). $\mathrm{SO}_{2}$ : sulphur dioxide. *: $\mathrm{p}<0.05$ by paired t-test, air versus $\mathrm{SO}_{2}$ in normal subjects. 
the process of neurogenic inflammation [13], although this remains to be proven for the human airway [3]. Support for the latter explanation has come from work demonstrating that irritant nasal stimulation can increase total pulmonary resistance by inducing constriction while, at the same time, bronchodilatation occurs in the lower airways [14]. This disparity between the laryngeal response and that of the lower conducting airways suggests that a single, vagally mediated mechanism is unlikely to be responsible and points to a local effect such as neurogenic inflammation.

The authors suggest that the present findings of autonomic changes are consistent with the existence of both these pathways (fig. 1). It is proposed that the primary autonomic impact that has been measured with exposure to $\mathrm{SO}_{2}$, is change in $\mathrm{HF}$ power. This is balanced by changes in LF power and consequently no overall change in lung function is seen. In normal subjects, the predominant pathway would appear to be through the RAR/C-fibre route, resulting in a central nervous system reflex with increase in vagal tone (increased HF power). In the subjects with asthma, it is proposed that local (proximal) airway narrowing (possibly through neurogenic inflammation) is the dominant response, observations of reduced HF power (i.e. reduced vagal tone) reflecting the CNS mediated, compensatory bronchodilatation of distal airways. The reduction in HF power is balanced by a reduction in LF power and thus no net change in measured lung function. This adds support to the hypothesis that neurogenic inflammation may be an important mec- hanism for airway narrowing in asthma in response to inhalation of $\mathrm{SO}_{2}$. The relative sensitivity of subjects with asthma to $\mathrm{SO}_{2}$ may reflect the increased exposure of their mucosal sensory nerve endings, due to the epithelial shedding, characteristic of asthma [15].

This hypothesis needs further exploration but, if shown to hold, would have implications beyond the understanding of the mechanisms of control of airway diameter in normal subjects and in subjects with asthma. Air pollution exposure has been shown to be associated with increased morbidity and mortality from both respiratory and cardiovascular diseases [16-20]. While the respiratory effects of air pollution have been intuitive, understanding the mechanisms mediating cardiovascular effects has proven elusive. A number of potential mechanisms have been proposed, including the dynamic reduction of heart rate variability on pollutant exposure, with reduced HRV being associated with an increased risk of death following myocardial infarction [21] and in patients with heart failure [22]. The present findings and those of others [23-26] suggest that pollutant exposure can provoke autonomic responses and that these responses may differ between subgroups of the population. It is possible that these autonomic responses may have trivial cardiovascular effects in healthy people, but may have more important consequences in those with underlying heart disease. Conversely it may be the inability of a diseased heart to respond to these autonomic modulations that mark individuals as being at increased risk of nonrespiratory morbidity or mortality during pollutant episodes.

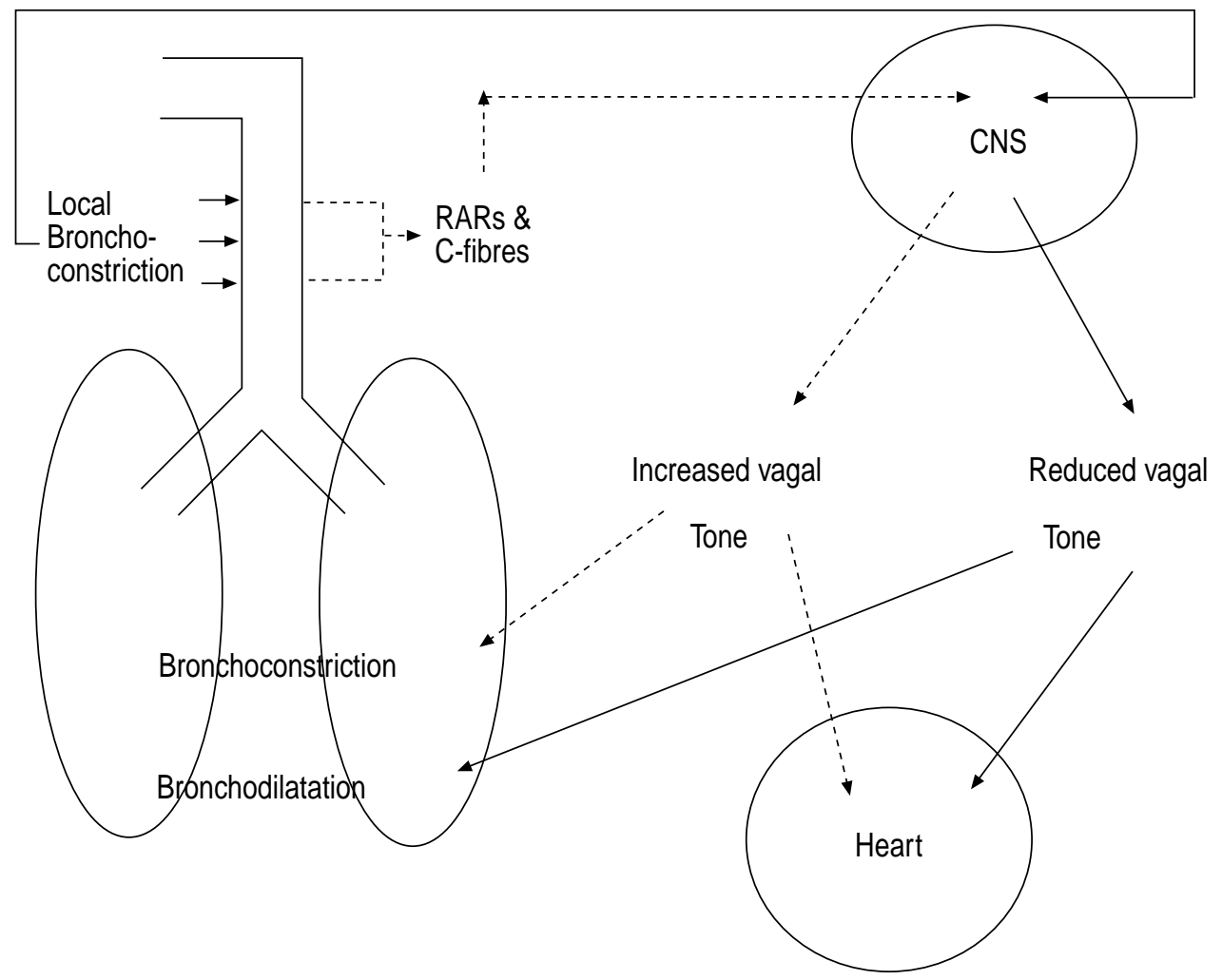

Fig. 1. - Proposed autonomic pathways of sulphur dioxide mediated bronchoconstriction in normal and asthma subjects. $\longrightarrow$ : dominant pathway in asthmatic subjects; - - - dominant pathway in normal subjects; RARs: rapidly adapting receptors; CNS: central nervous system. 


\section{References}

1. Anderson HR, Spix C, Medina S, et al. Air pollution and daily admissions for chronic obstructive pulmonary disease in 6 European cities: results from the APHEA project. Eur Respir J 1997; 10: 1064-1071.

2. Committee on the Medical Effects of Air Pollutants. Handbook on air pollution and health London: HM Stationary office, 1997.

3. Advisory Group on Medical Aspects of Air Pollution Episodes. Second Report: Sulphur dioxide, acid aerosols and particulates. London: HM Stationary office, 1992.

4. Lawther PJ, Macfarlane AJ, Waller RE, Brooks AGF. Pulmonary function and sulphur dioxide, some preliminary findings. Environ Res 1975; 10: 355-367.

5. Linn WS, Avol EL, Peng RC, Shamoo DA, Hackney JD. Replicated dose-response study of sulfur dioxide effects in normal, atopic, and asthmatic volunteers. Am Rev Respir Dis 1987; 136: 1127-1134.

6. Costa DL, Schelegle ES. Irritant air pollutants. In: Swift DL, Foster WM, eds. Air Pollutants and the Respiratory Tract. Lung Biology in Health and Disease Vol. 128. New York, Marcel Dekker, 1999; 119 146.

7. Nadel JA, Salem H, Tamplin B, Tokiwa Y. Mechanism of bronchoconstriction during inhalation of sulfur dioxide. J Appl Physiol 1965; 20: 164-167.

8. Korpas J, Tomori Z. Cough and other respiratory reflexes. Basel, Karger, 1979.

9. Task force of the European Society of Cardiology and The North American Society of Pacing and Electrophysiology. Heart Rate Variability; Standards of measurement, physiological interpretation, and clinical use. Eur Heart $J$ 1996; 17: 354-381.

10. Tunnicliffe WS, Mark D, Harrison R, Ayres JG. A system for the generation and head-only delivery of submicronic particles for the study of the health effects of particulate air pollution. Eur Respir J 1998; 12: Suppl. 28, 335s.

11. Overton JH, Miller FJ. Absorption of inhaled reactive gases. In: Gardner DE, Crapo JD, Massaro EJ, eds. Toxicology of the Lung. New York, Raven Press, 1988; 477-507.

12. Coleridge HM, Coleridge JCG. Reflexes evoked from tracheobronchial tree and lungs. In: Handbook of Physiology. Cherniack NS and Widdecombe M, eds. Bethesda, Am Physiol Soc, 1986, pp. 395-429.
13. Barnes PJ. Neural mechanisms in asthma. Br Med Bull 1992; 48: 149-168.

14. Wicker JH, Kern EB. The nasopulmonary reflex in the awake animal. Ann Otol 1973; 82: 355-358.

15. White SR, Leef AR. Epithelial damage in asthma. In: Asthma and rhinitis. Busse WW, Holgate ST, eds. Boston, Blackwell Scientific Publications. 1995; 599-611.

16. Wordley J, Walters S, Ayres JG. Short term variations in hospital admissions and mortality and particulate air pollution. Occup Environ Med 1997; 54: 108-116.

17. Poloniecki JD, Atkinson RW, de Leon AP, Anderson HR. Daily time series for cardiovascular hospital admissions and previous day's air pollution in London, UK. Occup Environ Med 1997; 54: 535-540.

18. Burnett RT, Dales R, Krewski D, Vincent R, Dann T, Brook JF. Association between ambient particulate sulfate and admissions to Ontario hospitals for cardiac and respiratory disease. Am J Epidemiol 1995; 142: 1522.

19. Dockery DW, Pope CA III. Acute respiratory effects of particulate air pollution. Annu Rev Public Health 1994; 15: 107-132.

20. Schwartz J. Air pollution and daily mortality: A review and mete analysis. Environ Res 1994; 64: 36-52.

21. Bigger JT, Fleiss L, Steinman RC, Rolnitzky LM, Kleiger RE, Rottman JN. Frequency domain measures of heart period variability and mortality after myocardial infarction. Circulation 1992; 85: 164-171.

22. Nolan J, Batin PD, Andrews R, et al. Reduced heart rate variability and mortality in chronic heart failure. Circulation 1996; 94: 498.

23. Dockery DW, Pope CA III, Kanner RE, Villegas GM, Schwartz J. Daily changes in oxygen saturation and pulse rate associated with particulate air pollution and barometric pressure. Health Effects Institute Report 1999; 83: 1-19.

24. Liao D, Creason J, Shy C, Williams R, Watts R, Zweidinger R. Daily variation of particulate air pollution and poor cardiac autonomic control in the elderly. Environ Health Perspect 1999; 107: S21-S25.

25. Lovett EG, Verrier RL, Coull B, et al. Alteration of canine heart rate variability (HRV) during exposure to concentrated ambient air particles (CAPs). Am J Respir Crit Care Med 1999; 159: A30.

26. Godleski JJ, Nearing BD, Killingsworth CR, et al. Increased cardiac vulnerability during exposure to inhaled environmental particles. Health Effects Institute Annual Meeting, Boston, Massachusetts, May 1998. Boston, MA: Health Effects Institute, 1998. 